\title{
Atividade antibacteriana in vitro de extratos de alho nirá (Allium tuberosum Rottler ex Spreng.)
}

\author{
ARAÚJO, C.A. ${ }^{1}$; CARVALHO, H.H.C. ${ }^{2}$; SOUTO, S.A. ${ }^{2}$; SOBREIRO, A.A. ${ }^{2}$; WIEST, J.M. ${ }^{1,2^{*}}$ \\ ${ }^{1}$ Universidade Federal do Rio Grande do Sul, Porto Alegre, Rio Grande do Sul, Programa de Pós-Graduação em \\ Ciências Veterinárias ${ }^{2}$ Universidade Federal do Rio Grande do Sul, Porto Alegre, RS / Brasil, Instituto de Ciência \\ e Tecnologia dos Alimentos * Correspondência: José M.Wiest - ICTA/UFRGS, Campus do Vale, Av. Bento Gonçalves \\ 9.500, Caixa Postal 15.090 CEP 91.505-970 Porto Alegre / RS / Brasil jmwiest@ufrgs.br
}

\begin{abstract}
RESUMO: Com o objetivo de demonstrar a influência da condimentação sobre a Validade Preditiva dos Resultados Negativos do diagnóstico de bactérias transmissíveis por alimentos, determinouse, in vitro, a intensidade de atividade de inibição bacteriana (IINIB) e a intensidade de atividade de inativação bacteriana (IINAB) de três acessos de Allium tuberosum Rottler ex Spreng. - Liliaceae alho "nirá", originários da região metropolitana de Porto Alegre, Rio Grande do Sul. O extrato etanólico à $50 \%$ destes diferentes acessos (alcoolaturas com evaporação do etanol em sistema rotavapor com reconstituição hídrica sob assepsia) foi testado, através de testes de diluição em sistema de tubos múltiplos, sobre inóculos padronizados de Staphylococcus aureus (ATCC 25.923), Enterococcus faecalis (ATCC 19.433), Salmonella enteritidis (ATCC 11.076), Escherichia coli (ATCC 11.229). Os testes revelaram atividade antibacteriana seletiva sobre os diferentes inóculos Gram-negativos, que atingiram inibição e inativação máximas e permanentes para Salmonella após 48 horas, e, para Escherichia coli, após 72 horas de exposição. As bactérias Gram-positivas, Staphylococcuse Enterococcus, apresentaram resistência total frente aos extratos etanólicos Não houve diferença significativa entre si quanto aos tempos de atuação, quanto a Salmonella e Escherichia, quanto à presença ou ausência de desinibidores bacterianos, havendo, entretanto, diferença significativa entre os acessos de alho nirá.
\end{abstract}

Palavras-chave: Allium tuberosum, condimentos vegetais, atividade antibacteriana, inibição bacteriana por plantas, inativação bacteriana por plantas

\begin{abstract}
In vitro antibacterial activity of "Nira" garlic extracts (Allium tuberosum Rottler ex-Spreng.). To demonstrate the influence of seasoning on the Predictive Validity of Negative Results in the diagnosis of bacteria transmissible through food, the intensity of bacterial inhibition activity (IINIB) and the intensity of bacterial inactivation activity (IINAB) were determined in vitro for three sources of Allium tuberosum Rottler ex Spreng. - Liliaceae ("Nira" Garlic) from the metropolitan area of Porto Alegre, Rio Grande do Sul State, Brazil. The 50\% ethanol extract of those different sources (alcoholature obtained with the evaporation of ethanol in rotavapor system with aseptic hydric-reconstitution) was assessed through dilution tests in multiple tube series against standardized inocula of Staphylococcus aureus (ATCC 25923), Enterococcus faecalis (ATCC 19.433), Salmonella enteritidis (ATCC 11.076) and Escherichia coli (ATCC 11.229). Tests revealed selective antibacterial activity against the different Gram-negative inocula, which reached maximum and permanent inhibition and inactivation for Salmonellaafter 48 hours and for Escherichia coli after 72 hours of exposition. The Gram-negative bacteria, Staphylococcus and Enterococcus, presented total resistance to the ethanol extracts. There were no significant differences among activity times for Salmonella and Escherichia, as well as between presence and absence of bacterial non-inhibitors. However, there were significant differences among "Nira" garlic sources.
\end{abstract}

Key words: Allium tuberosum, plant spices, antibacterial activity, bacterial inhibition, bacterial inactivation

\section{INTRODUÇÃO}

Plantas condimentares e aromáticas e seus diferentes extratos, acrescidos a preparações alimentares, podem constituir variáveis intervenientes

no diagnóstico de doenças bacterianas transmissíveis por alimentos, interferindo na validade preditiva dos resultados negativos, ou seja, através

Recebido para publicação em 06/05/2008

Aceito para publicação em 14/10/2008 
da inibição bacteriana ou bacteriostasia induzida, serem simulados resultados falso-negativos quando de inquéritos epidemiológicos de surtos. Neste sentido Carvalho et al. (2005), na região metropolitana de Porto Alegre, Rio Grande do Sul, pesquisando atividade antibacteriana em 32 plantas com indicativo etnográfico condimentar, demonstraram em 12 delas (em quatro espécies de Capsicum, em duas de Allium e de Origanum, em uma de Artemísia, Salvia, Thymus e Petroselinum) ação biológica in vitro, intensa e seletiva, sobre diferentes inóculos bacterianos, entre eles Salmonella e Staphylococcus. Especificamente em relação ao alho nirá (Allium tuberosum - Rottler exSprengl. - Liliaceae) os autores observaram, frente a S. aureuse E. faecalis, uma inibição (bacteriostasia) média de 103 UFC mL-1, bem como, a ausência de inativação (bactericidia). Frente a Salmonella enteritidis e Escherichia coli, entretanto, observaram inibição e inativação máximas (107 UFC mL-1). Os autores avaliaram a validade preditiva destes resultados negativos por inibição ou bacteriostasia, classificando-os como falso-negativos, prejudicando a avaliação e as condutas nos surtos toxinfectivos em estudo epidemiológico.

Leuschner \& Zamparini (2002) relataram que a adição de $1 \%$ de bulbo de alho à maionese conseguiu reduzir a concentração de células viáveis de Salmonella enteritidis durante três dias, por um fator logarítmico, mas, aplicando-se o método de isolamento do agente em 25 gramas de amostra, constataram a presença constante da Salmonella nas amostras testadas durante 10 dias de estocagem à $25^{\circ} \mathrm{C}$, comprovando o estado de bacteriostasia ou de latência do agente no alimento.

O uso medicinal dos diferentes tipos de alho como antimicrobianos é destacado por Cellini et al. (1996), atribuindo a alicina, um componente sulfuroso, a intensa atividade descrita. Ankri \& Mirelman (1999) reforçam estas observações, ressaltando a ação significativa sobre linhagens de Escherichia coli enterotoxicogênicas, multidroga-resistentes.

Diferentes espécies de Allium ssp, dentre as cerca de 500 descritas, entre elas os diferentes bulbos de cebolas e o alho propriamente dito, os tipos foliares como o "nirá" - "japonês" ou o "jiucai" - "chinês, são empregados largamente como alimento, condimentos ou especiarias, ou mesmo medicamentos, mormente no hemisfério norte. Estas plantas constituem fonte abundante de saponinas esteroidais, de alcalóides, bem como de compostos sulfurosos. O alho "nirá" ou "jiucai", Allium tuberosum Rottler ex Spreng. - Liliaceae - constitui-se em alimento diário consumido geralmente verde, recém colhido, para a grande maioria da população chinesa, distribuindose em todo o continente, sendo utilizado não somente como alimento, mas como medicamento, constituindo- se este país o maior produtor mundial. Além do uso como alimento, tanto as porções foliares, mas, principalmente, as sementes, possuem reputada indicação na medicina tradicional chinesa como tratamento da impotência masculina e das emissões noturnas. Os autores referem ainda que, segundo o Dicionário das Drogas Chinesas, a parte foliar deste alho é utilizada para o tratamento de dores abdominais, diarréia, hematemese, agressões de ofídios e para tratamento da asma, enquanto que as sementes se destinam, prioritariamente, na medicina popular, como tônico e afrodisíaco. No ano de 2001 o governo chinês reconheceu oficialmente e passou a indicar o consumo desta espécie de alho, tanto como alimento como medicamento em todo o país (Hu et al., 2006).

Sang et al. (2003) remetem a estudos fitoquímicos de "jiucai" ou alho chinês, indicando que as saponinas esteroidais presentes neste alho são glicosídios que ocorrem espontaneamente, com propriedades de formação de espuma, com acentuada atividade hemolítica, toxicidade para peixes e formação de complexos com a colesterina. Nos anos recentes, segundo os autores, os glicosídios esteroidais vem merecendo crescente interesse pelo largo espectro de sua ação biológica em seres vivos, incluindo ação antidiabética, antitumoral, antitussígena, bem como de inibição de agregação de plaquetas.

No Brasil, segundo Lima et al. (2005), Allium tuberosum, com sinonímia de $A$. odorum, é conhecido como cebolinha chinesa, sendo largamente utilizado como condimento, cultivado pelos japoneses e seus descendentes nas regiões sul, sudeste e centrooeste.

O presente estudo propôs determinar in vitro a atividade antibacteriana de solução conservante a partir de extração etanólica (alcoolatura com evaporação do etanol em sistema rotavapor com reconstituição hídrica posterior sob condições de assepsia) de três acessos de Allium tuberosum Rottler exSpreng. ("alho nirá" ou "alho japonês", "jiucai ou alho chinês") - Liliaceae, originários da região metropolitana de Porto Alegre, Rio Grande do Sul, frente a agentes bacterianos padrões internacionais de interesse em alimentos, atividade esta expressa como IINIB (intensidade de inativação bacteriana/ bacteriostasia) e como IINAB (intensidade de inativação bacteriana/ bactericidia), relacionando-a a preditividade dos resultados negativos quando do diagnóstico destes agentes em alimentos. Em síntese, manipularam-se as variáveis: bactérias gramnegativas e positivas, os acessos da planta, os tempos de confrontação e a presença ou ausência de desinibidores bacterianos, permanecendo constantes a forma de extração (alcoolatura) e a concentração final do extrato (50\%). 


\section{MATERIAL E MÉTODO}

Foram feitas coletas de Allium tuberosumRottler ex Spreng. (alho "nirá" ou alho "japonês", "jiucai" ou alho "chinês") - Liliaceae - em três diferentes locais na região Metropolitana de Porto Alegre, em Viamão, Eldorado do Sul e Lami, respectivamente. As coletas foram realizadas junto a propriedades de agricultura familiar, em cultivos agroecológicos, no período entre junho/2005 e novembro/2006.

As plantas foram caracterizadas e identificadas botanicamente, a partir de exsicatas segundo Ming (1996), pela botânica Silvia Marodin (CRBioRS-17268), sendo posteriormente encaminhadas para registro e depósito junto ao Herbário do Instituto de Biociências/ Departamento de Botânica da UFRGS, Porto Alegre, Rio Grande do Sul, Brasil, recebendo o número de registro 128941.

Para a obtenção do extrato alcoólico, folhas e talos verdes dos diferentes acessos de alho foram cortadas grosseiramente e colocadas em álcool etílico de cereais à $96^{\circ} \mathrm{GL}$, segundo Farmacopéia Brasileira (1959), na proporção de $400 \mathrm{~g}$ de planta verde para $1000 \mathrm{~mL}$ de álcool. Em um prazo mínimo de quinze dias, estabelecido para maturação da alcoolatura, a fase líquida desta mistura foi submetida à destilação fracionada sob pressão reduzida em sistema rotavapor, desprezando-se a porção alcoólica por evaporação, com posterior reconstituição hídrica do extrato restante, reestabelecendo-se assim as concentrações iniciais da planta verde neste extrato vegetal, a ser posteriormente submetido a desafios bacteriológicos. Para o controle permanente da assepsia destes procedimentos, determinou-se a esterilidade de todos os extratos estudados, retirandose alíquota de $5 \mathrm{~mL}$, semeada em tubos de Caldo $\mathrm{BHI}$ (Brain Heart Infusion, OXOID), incubados aerobiamente à $37^{\circ} \mathrm{C}$ por até 48 horas, confirmandose os resultados por semeadura em Agar Nutriente (Nutrient Agar, OXOID).

Os extratos foram desafiados in vitro com linhas de diluições sucessivas de amostras de bactérias padrões daAmerican Type Culture Colletion (ATCC), sendo duas Gram-positivas: Staphylococcus aureus (ATCC 25.923) e Enterococcus faecalis (ATCC 19.433), bem como duas Gram-negativas: Escherichia coli (ATCC 11.229) e Salmonella enteritidis (ATCC 11.076), provenientes da coleção-bacterioteca do Laboratório de Higiene do Instituto de Ciências e Tecnologia dos Alimentos/UFRGS, mantidas em meios nutrientes (NutrientAgar e BHI-Agar), reativadas em meio de cultura contendo infusão de cérebro e coração (BHI) a $36^{\circ} \mathrm{C}$ por 18 a 24 horas de incubação aeróbia, atingindo no mínimo 1,0 x 108 UFC mL-1, para posterior desafio com os extratos vegetais, devidamente fracionadas através de diluições seriais logarítmicas/ concentrações bacterianas, controladas biometricamente, segundo Cavalli-Sforza (1974)

Para determinação da atividade antibacteriana dos extratos de Allium tuberosum, expressa como intensidade de atividade de inibição bacteriana (IINIB) e intensidade de atividade de inativação bacteriana (IINAB), utilizou-se o teste de diluição segundo Deutsche Veterinaermedizinische Gesellschaft/ Sociedade Alemã de Medicina Veterinária (DVG, 1981), com base na técnica do sistema de tubos múltiplos, modificada por Avancini (2002), retomada por Souza \& Wiest (2007) e Avancini \& Wiest (2008), confrontando os extratos com oito ou nove diluições seriais logarítmicas ( $10^{1}$ a 108 ou 109 UFC $\mathrm{mL}^{-1}$ ) dos inóculos bacterianos, o que dependeu da concentração atingida pela cultura-mãe bacteriana após 24 horas de incubação, consideradas desde a sua ativação a partir das coleções-padrão mantidas em bacterioteca. A sensibilidade ou a resistência da bactéria submetida ao desafio frente ao extrato vegetal, foi verificada através da presença ou ausência de microorganismos viáveis em placas de Petri contendo agar nutriente, sendo este controle realizado por inoculação, através de alça bacteriológica calibrada $(0,05 \mathrm{~mL})$ e incubação subseqüente por 24 horas, de alíquotas dos diferentes tubos múltiplos, após 24, 48, 72 e 144 horas de sua incubação aeróbia a 37C (DVG,1981; Avancini, 2002; Souza \& Wiest, 200; Avancini \& Wiest, 2008).

Entende-se por IINIB, o resultado do desafio da bactéria com a solução antibacteriana/ extrato vegetal em meio específico (BHI), e IINAB, o mesmo resultado, porém sob a influência dos desinibidores bacterianos acrescidos ao mesmo meio bacteriológico, o BHI, conforme recomendações da DVG (1980),

TABELA1. Valores ordinais arbitrários de intensidade de atividade atribuídos às variáveis intensidade da atividade de inibição bacteriana/bacteriostasia (IINIB) e intensidade de atividade de inativação bacteriana/bactericidia (IINAB) e suas correspondentes diluições e doses infectantes dos inóculos bacterianos.

\begin{tabular}{lcccccccccl}
\hline 9 & 8 & 7 & 6 & 5 & 4 & 3 & 2 & 1 & 0 & Variáveis ordinais de intensidade de atividade \\
\hline $10^{-1}$ & $10^{-2}$ & $10^{-3}$ & $10^{-4}$ & $10^{-5}$ & $10^{-6}$ & $10^{-7}$ & $10^{-8}$ & $10^{-9}$ & & UFC mL $L^{-1}-$ diluições dos inóculos inibidas ou inativadas \\
\hline $10^{8}$ & $10^{7}$ & $10^{6}$ & $10^{5}$ & $10^{4}$ & $10^{3}$ & $10^{2}$ & $10^{1}$ & 1 & n.a & UFC mL Ul $^{-1}$ doses infectantes inibidas ou inativadas \\
\hline
\end{tabular}

n.a = ausência de atividade antibacteriana UFC $\mathrm{mL}^{-1}=$ Unidades Formadoras de Colônias $\mathrm{mL}^{-1}$ 
Andrade \& Macedo (1996), Reybrouck (1979 e 1998). Estes valores são, segundo Avancini (2002), indicadores quantificáveis através de variáveis ordinais arbitrárias, embora essencialmente qualitativos, da atividade biológica inibitória/ bacteriostasia ou inativadora/ bactericidia de diferentes soluções antibacterianas, neste caso os extratos vegetais, sobre os microrganismos em teste.

Os resultados de IINIB e IINAB foram representados por variáveis ordinais arbitrárias, que assumiram valores de 9 (nove) a 0 (zero), indicando a intensidade da atividade antibacteriana de inibição e/ ou de inativação, como demonstra a Tabela 1.

A avaliação dos resultados obtidos das variáveis de IINIB e de IINAB para os diferentes acessos de alho confrontados in vitro com os agentes bacterianos foi verificada através de análise estatística descritiva e análise de variância, com complementação pelo teste de Tukey, segundo Callegari-Jacques (2004).

\section{RESULTADO E DISCUSSÃO}

O teste de Tukey para comparar os extratos dos três acessos de alho (Tabela 2), independentemente do meio bacteriológico, da presença ou ausência de desinibidores e do tempo de exposição, demonstrou diferença significativa para o acesso coletado da região de Viamão em relação aos outros dois acessos $(p<0,05)$, estes, por sua vez, sem diferença entre si $(p>0,05)$. A análise de variância, em relação aos dois meios de cultivo bacteriológico, não demonstrou diferença significativa entre eles $(p=0,05)$. Especificamente, para cada um dos acessos de alho, independente dos meios, o teste não demonstrou

TABELA2. Intensidade da atividade de inibição bacteriana (IINIB) e intensidade de atividade de inativação bacteriana (IINAB) de extrato etanólico (alcoolatura)* a 50\% de diferentes acessos de Allium tuberosum Rottler ex Spreng. (alho "nirá", "jiucai") - Liliaceae, sobre Escherichia coli (ATCC 11.229), determinadas em dois meios de cultivo bacteriano, segundo tempo de exposição.

\begin{tabular}{|c|c|c|c|c|c|c|}
\hline \multicolumn{7}{|c|}{ Escherichia coli (ATCC) } \\
\hline & & \multicolumn{2}{|c|}{$\mathrm{PCA}^{(1)}$} & \multicolumn{2}{|c|}{ Chromocult ${ }^{(2)}$} & \multirow[b]{3}{*}{ Média $^{(6)}$} \\
\hline \multirow{2}{*}{\multicolumn{2}{|c|}{ Acesso/Tempo exposição }} & \multicolumn{2}{|c|}{ Média $^{(4)} 6,45^{a}$} & \multicolumn{2}{|c|}{ Média $^{(4)} 6,50^{\mathrm{a}}$} & \\
\hline & & IINIB & IINAB & IINIB & IINAB & \\
\hline \multirow[t]{4}{*}{ Eldorado do Sul } & $24 \mathrm{~h}$ & $7^{\star \star}$ & 6 & 6 & 6 & $6,25 c$ \\
\hline & $48 \mathrm{~h}$ & 8 & 7 & 7 & 7 & $7,25 \mathrm{c}$ \\
\hline & $72 \mathrm{~h}$ & 8 & 8 & 8 & 8 & $8,00 \mathrm{c}$ \\
\hline & $144 \mathrm{~h}$ & 8 & 8 & 8 & 8 & $8,00 \mathrm{c}$ \\
\hline \multirow[t]{2}{*}{ Média ${ }^{(3)}$} & $7,38 \mathrm{~A}$ & Média ${ }^{(5)}$ & Média $^{(5)}$ & Média ${ }^{(5)}$ & Média ${ }^{(5)}$ & \\
\hline & & $7,75 \mathrm{~b}$ & $7,25 \mathrm{~b}$ & $7,25 \mathrm{~b}$ & $7,25 \mathrm{~b}$ & \\
\hline \multirow[t]{4}{*}{ Lami } & $24 \mathrm{~h}$ & 4 & 3 & 4 & 5 & $4,08 d$ \\
\hline & $48 \mathrm{~h}$ & 5 & 5 & 5 & 6 & $5,25 \mathrm{~cd}$ \\
\hline & $72 \mathrm{~h}$ & 5 & 6 & 5 & 6 & $5,50 \mathrm{~cd}$ \\
\hline & $144 \mathrm{~h}$ & 5 & 7 & 5 & 7 & $6,00 \mathrm{c}$ \\
\hline \multirow[t]{2}{*}{ Média ${ }^{(3)}$} & $6,48 \mathrm{~A}$ & Média $^{(5)}$ & Média $^{(5)}$ & Média ${ }^{(5)}$ & Média ${ }^{(5)}$ & \\
\hline & & $4,75 b$ & $5,25 b$ & $4,75 b$ & $6,0 \mathrm{~b}$ & \\
\hline \multirow[t]{4}{*}{ Viamão } & $24 h$ & 5 & 6 & 6 & 5 & $5,50 d$ \\
\hline & $48 \mathrm{~h}$ & 7 & 7 & 7 & 7 & $7,00 \mathrm{c}$ \\
\hline & $72 \mathrm{~h}$ & 7 & 8 & 7 & 8 & $7,50 \mathrm{c}$ \\
\hline & $144 \mathrm{~h}$ & 7 & 8 & 7 & 8 & $7,50 \mathrm{c}$ \\
\hline \multirow[t]{2}{*}{ Média $^{(3)}$} & $5,19 \mathrm{~B}$ & Média $^{(5)}$ & Média $^{(5)}$ & Média ${ }^{(5)}$ & Média ${ }^{(5)}$ & \\
\hline & & $6,50 \mathrm{~b}$ & $7,25 b$ & $6,75 b$ & $7,00 \mathrm{~b}$ & \\
\hline
\end{tabular}

(IINIB) Intensidade da atividade de inibição bacteriana: o resultado do desafio da bactéria com a solução antibacteriana/ extrato vegetal em meio bacteriológico (BHI); (IINAB) Intensidade de atividade de inativação bacteriana: o resultado do desafio da bactéria com a solução antibacteriana/ extrato vegetal, porém sob a influência dos desinibidores bacterianos acrescidos ao mesmo meio bacteriológico, o $\mathrm{BHI}$; (1): - PCA (Plat Count Agar, HIMEDIA); (2): - Chromocult ( Chromocult Coliform Agar, MERCK); (3): - letras maiúsculas iguais ("A" e/ ou "B") na mesma coluna indicam que não há diferença significativa $(p>0,05)$; (4): - letras minúsculas iguais em sobrescrito (" a ") na mesma linha indicam que não há diferença significativa $(p>0,05) ;(5)$ : - letras minúsculas iguais ("b") na mesma linha indicam que não há diferença significativa ( $p>0,05)$; (6): - letras minúsculas iguais ("c" e ou "d") na mesma coluna indicam que não há diferença significativa $(p>0,05)$; $\left({ }^{*}\right)$ : - etanol evaporado em sistema rotavapor com reconstituição hídrica, sob assepsia; $\left.{ }^{* *}\right)$ : - variáveis ordinais arbitrárias com valores de 8 (oito) a 0 (zero), indicando as diferentes concentrações/ diluições do inóculo de Escherichia coli (ATCC 11.229 / concentração inicial de $2,3.10^{8}$ U.F.C $\mathrm{mL}^{-1}$, valor médio de três repetições) 
diferença significativa entre a presença (IINAB) e ausência de desinibidores (IINIB) em $p=0,05$.

Para o acesso coletado na região de Eldorado, independente dos meios e da presença ou ausência de desinibidores, a diferença entre os quatro tempos de confrontação não mostrou-se significativa $(p<0,05)$. Para o acesso coletado na região do Lami, comparando-se os resultados de 24, 48 e 72 horas de atuação entre si, não houve diferença entre eles ( $p<0,05)$, o que também foi observado comparando-se entre si os resultados de 48, 72 e 144 horas; os tempos 48 e 72 horas de atuação, por sua vez, comparados entre si, também não demonstraram diferença $(p>0,05)$. Para o acesso coletado na região de Viamão houve diferença entre o tempo 24 horas quando comparado com os demais três tempos de atuação $(p<0,05)$, não havendo diferença entre estes três últimos $(p<0,05)$.

A Tabela 3 apresenta os valores de IINIB e de IINAB determinados pelo extrato etanólico a $50 \%$ do acesso de alho nirá coletado na região de Eldorado do Sul sobre as bactérias em estudo, segundo diferentes tempos de exposição.

As bactérias gram-positivas demonstraramse completamente resistentes, valor arbitrário atribuído zero ( 0 = não atividade), impedindo análise estatística. Comparando as duas bactérias gramnegativas, independente do tempo e da presença ou ausência de desinibidores, não observou-se diferença significativa entre elas $(p=0,05)$.

Os resultados revelam capacidade seletiva do extrato de alho "nirá" sobre inóculos Gramnegativos, que atingiram inibição e inativação máxima e permanente para Salmonella às 48 horas de confrontação e para $E$. coli somente às 72 horas, respectivamente, embora sem significância estatística.

As diferenças entre IINIB (inibição bacteriana/ bacteriostasia) e IINAB (inativação bacteriana/ bactericidia), tanto para Salmonella após 24 horas, como para Escherichia coli após 24 e 48 horas, permitem questionar a preditividade dos resultados negativos no diagnóstico bacteriológico destes agentes em alimentos condimentados por alho "nirá". Nos testes diagnósticos convencionais, estabelecidos pela legislação vigente no país, motivado pela não utilização de desinibidores bacterianos nestes testes, o não desenvolvimento bacteriano pela intensa inibição/bacteriostasia interveniente demonstrada, pelo menos por determinado tempo, pode induzir, através da emissão de laudo de análise bacteriológica, a certificação

TABELA3. Intensidade da atividade de inibição bacteriana (IINIB) e intensidade da atividade inativação bacteriana (IINAB) de extrato etanólico (alcoolatura) * a 50\% do acesso coletado na região de Eldorado do Sul, de Allium tuberosum Rottler ex Spreng. (alho "nirá", "jiucai") - Liliaceae, sobre bactérias de interesse em alimentos, segundo diferentes tempos de exposição.

\begin{tabular}{|c|c|c|c|c|c|c|c|c|c|}
\hline \multicolumn{10}{|c|}{ Bactérias ATCC } \\
\hline \multirow[t]{2}{*}{$\begin{array}{l}\text { Tempo de } \\
\text { Exposição }\end{array}$} & \multicolumn{2}{|c|}{ S. aureus ${ }^{(1)}$} & \multicolumn{2}{|c|}{ E. faecalis ${ }^{(2)}$} & \multicolumn{2}{|c|}{$\begin{array}{l}\text { Salmonella } \\
\text { enteritidis }^{(3)}\end{array}$} & \multicolumn{2}{|c|}{$\begin{array}{l}\text { Escherichia } \\
\text { coli }^{(4)}\end{array}$} & \multirow[b]{2}{*}{ Média $^{(5)}$} \\
\hline & IINIB & IINAB & IINIB & IINAB & IINIB & IINAB & IINIB & IINAB & \\
\hline $24 h$ & $0^{(* *)}$ & 0 & 0 & 0 & 8 & 7 & 8 & 7 & $7,50 \mathrm{a}$ \\
\hline $48 h$ & 0 & 0 & 0 & 0 & 8 & 8 & 9 & 8 & $8,25 \mathrm{a}$ \\
\hline $72 \mathrm{~h}$ & 0 & 0 & 0 & 0 & 8 & 8 & 9 & 9 & $8,50 \mathrm{a}$ \\
\hline $144 \mathrm{~h}$ & 0 & 0 & 0 & 0 & 8 & 8 & 9 & 9 & $8,50 \mathrm{a}$ \\
\hline Média ${ }^{(6)}$ & - & - & - & - & $8,00 \mathrm{~A}$ & $7,75 \mathrm{~A}$ & $8,75 A$ & $8,25 \mathrm{~A}$ & \\
\hline Média ${ }^{(7)}$ & & - & & - & & & 8,5 & $0^{a}$ & \\
\hline
\end{tabular}

(IINIB) Intensidade da atividade de inibição bacteriana: o resultado do desafio da bactéria com a solução antibacteriana/ extrato vegetal em meio bacteriológico (BHI); (IINAB) Intensidade de atividade de inativação bacteriana: o resultado do desafio da bactéria com a solução antibacteriana/ extrato vegetal, porém sob a influência dos desinibidores bacterianos acrescidos ao mesmo meio bacteriológico, o BHI; (1): - inóculo /concentração inicial de Staphylococcus aureus (ATCC 25.923) de 6,75 .108 UFC $\mathrm{mL}^{-1}$ ( valor de uma repetição); (2): - inóculo /concentração inicial de Enterococcus faecalis ( ATTC 19.433) de 4,20 .108 UFC mL-1 (valor de uma repetição); (3): - inóculo / concentração inicial de Salmonella enteritidis (ATCC 11.076) de 6,6 .108 UFC mL-1 (valor médio de duas repetições); (4): - inóculo / concentração inicial de Escherichia coli (11.229) de 5,55 .109 UFC mL-1 ( valor médio de duas repetições); (5): - letras minúsculas iguais ("a") na mesma coluna indicam que não há diferença significativa entre os diferentes tempos de atuação, independente da bactéria Gramnegativa e da presença ou ausência de desinibidores bacterianos; (6): - letras maiúsculas iguais ("A") na mesma linha indicam que não há diferença significativa entre a presença ou ausência de desinibidores bacterianos, independente da bactéria Gram-negativa e do tempo de confrontação; (7): letras minúsculas iguais, sobrescritas ("â”) na mesma linha indicam que não há diferença significativa entre as bactérias Gram-negativas, independente do tempo de confrontação e da presença ou ausência de desinibidores bacterianos; ( $\left.{ }^{\star}\right)$ :etanol evaporado em sistema de rota-vapor com reconstituição hídrica sob assepsia; (**):- variáveis ordinais arbitrárias, com valores de 9 (nove) a 0 (zero), indicando as diferentes concentrações/ diluições dos inóculos bacterianos inibidos ou inativados. 
da ausência destas bactérias na alíquota de alimento sob análise, um resultado falso-negativo, quando, na realidade, as mesmas se encontram somente inibidas temporariamente, porém viáveis, não inativadas.

Em síntese, é possível concluir que os três acessos de Allium tuberosum Rottler ex Spreng. (alho "nirá) - Liliaceae, originais da região metropolitana de Porto Alegre, Rio Grande do Sul, apresentaram atividade antibacteriana seletiva in vitro, em seu extrato etanólico (alcoolatura com evaporação do etanol em sistema de rotavapor com reconstituição hídrica sob assepsia) na concentração de 50\%, apresentando um destes acessos diferença em relação a atuação dos demais, estes, por sua vez, sem diferença entre si. Staphylococcus aureus e Enterococcus faecalis mostraram resistência total ao extrato referido, enquanto que as bactérias gram-negativas Salmonella enteritidis e E. coli mostraram-se sensíveis, apresentando inibição e inativação significativas. A presença ou ausência de desinibidores bacterianos, as espécies bacterianas gram-negativas e os tempos de confrontação, quando comparados, independentemente, entre si próprios, não apresentaram diferenças significativas. A preditividade dos resultados negativos (falso-negativos) no diagnóstico destas bactérias Gram-negativas em alimentos pode ser influenciada pela bacteriostasia/inativação interveniente, sugerindo que dados epidemiológicoetnográficos relacionados com condimentação poderiam ser integrados à investigação diagnóstica e epidemiológica de surtos toxinfectivos alimentares com vistas a salmonelose, bem como ao controle de qualidade quanto a coliformes fecais em matérias-primas e produtos alimentícios em geral.

\section{AGRADECIMENTO}

Ao CNPq, pelo apoio financeiro ( processo 300 979/2005-3).

\section{REFERÊNCIA}

ANDRADE, N.J.; MACÊDO, J.A. Higienização na indústria de alimentos. São Paulo: VARELA, 1996. 182p.

ANKRI, S.; MIRELMAN, D. Antimicrobial properties of allicin from garlic. Microbes and Infection, v.1, n.2, p.1259, 1999.

AVANCINI, C.A.M. Saneamento aplicado em saúde e produção animal: etnografia, triagem da atividade antibacteriana de plantas nativas do Sul do Brasil e teses de avaliação do decocto de Hypericum caprifoliatum Cham e Schlecht - Hipericaceae (Guttiferae) - ("escadinha"/"sinapismo") para uso como desinfetante e antisséptico. 2002. 309p. Tese (Doutorado em Ciências Veterinárias) - Faculdade de Veterinária, Universidade Federal do Rio Grande do Sul, Porto Alegre. AVANCINI,C.A.M.; WIEST,J.M. Atividade desinfetante do decocto de Hypericum caprifoliatum Cham. e Schlecht.Gutiferae ("escadinha"/"sinapismo"), frente diferentes doses infectantes de Staphylococcus aureus (agente infeccioso em mastite bovina. Revista Brasileira de Plantas Medicinais, v.10, n.1, p.64-9, 2008.

CALLEGARI-JACQUES, L.M. Bioestatística: princípios e aplicações. Porto Alegre: Artmed, 2004. 255p.

CARVALHO, H.H.C.; CRUZ, F.T.; WIEST, J.M. Atividade antibacteriana em plantas com indicativo etnográfico condimentar em Porto Alegre, RS/Brasil. Revista Brasileira de Plantas Medicinais, v.7, n.3, p.25-32, 2005. CAVALLI-SFORZA, L. Biometrie. Stuttgart: Gustav Fisher, 1974. p.201-4.

CELLINI, L.D.I. et al. Inhibition of Helicobacter pylori by garlic extract. Immunology and Medical Microbiology, v.13, n.44, p.273-7, 1996.

DEUTSCHE VETERINÄRMEDZINISCHE GESELLSCHAFT/ SOCIEDADEALEMÃ DE MEDICINA VETERINÁRIA-DVG. Richtlinien zur Prüfung chemischer Desinfektionsmittel für die Veterinärmedizin/Normas para a testagem de desinfetantes químicos para a medicina veterinária. In: SCHLIESSER, T.; STRAUCH, D. Desinfektion in Tierhaltung, Fleisch- und Milschwirtschaft/Desinfecção na produção animal, em laticínios e em frigoríficos. Stuttgart: Enke Verlag, 1981. 455p.

FARMACOPÉIA dos Estados Unidos do Brasil. 2.ed. São Paulo: Siqueira, 1959.1265p.

HU, G.; LU, Y.; WEI, D. Chemical characterization of Chinese chive seed (Allium tuberosum Rottl.). Food Chemistry, v.99, n.4, p.693-7, 2006.

LEUSCHNER, R.; ZAMPARINI,J. Effects of spices on growth and surviral of Escherichia coli 0157 and Salmonella enterica sorovar Enteridis in borth model systems and mayonnaise. Food Control, v.13, n.6-7, p.399-404, 2002.

LIMA, M.LP. et al. Allium tuberosum como hospedeira de Puccinia alliino Brazil. Fitopatologia Brasileira, v.30, n.6, p.670, 2005.

MING, L.C. Coleta de plantas medicinais. In: DISTASI, L.C. Plantas Medicinais: arte e ciência. Um guia para o estudo interdisciplinar. São Paulo: Ed. UNESP, 1996. p.69-86.

REYBROUCK, G. Efficacy of inactivators against 14 desinfectant substances. Zentralblatt für Bakteriologie und Hygiene, v.68, p.480-92, 1979.

REYBROUCK, G. The testing of disinfectants. International Biodeterioration \& Biodegradation, v.41, p.269-72, 1998.

SANG, S. et al. New steroid saponins from the seeds of Allium tuberosumL. Food Chemistry, v.83, p.499-506, 2003. SOUZA, A.A.; WIEST, J.M. Atividade antibacteriana de Aloysia gratissima (Gill et Hook) Tronc. (garupá, evasanta), usada na medicina tradicional do Rio Grande do Sul - Brasil. Revista Brasileira de Plantas Medicinais, v.9, n.3, p.23-9, 2007. 